\title{
THE NEED FOR BEREAVEMENT SUPPORT PROGRAMMES IN THE WORKPLACE
}

\section{Vanagree Naidoo, Rina Delport}

\section{INTRODUCTION}

Bereavement is an almost universal human experience and strikes practically all people several times during the course of a life. This is viewed as the most stressful life event, which is often severely traumatic, affects all facets of a person's life and could last from weeks to years (Woof \& Carter, 1997:443).

Lindstrom (1983:2) offers a similar understanding and states that bereavement is a vastly multifaceted stressor that influences most parts of a person's life, including its psychological, physiological, sociological and existential-religious dimensions. It creates problems in areas where problems were hardly expected and for which the bereaved person might be unprepared. The terrible emotional turmoil and the behaviour evoked by bereavement is considered as basically normal, even when it includes manifestations which may appear as bizarre to nonmourners or persons from another culture. Grief, despite temporary ups and downs, normally fades over time, "normal life" is resumed and sometimes even improved. However, this course of events may go wrong, causing an impoverished state of life, or an activation or re-activation of psychiatric problems or conditions.

As a result of people coping with loss of a loved one in many different ways, for some the experience may lead to personal growth and for others it could lead to a deterioration in their normal functioning. There is no right way of coping with death. The way a person grieves depends on the personality of that person and the relationship with the person who has died (MedicineNet.com, 2007:1).

Grief and loss occur both at work and at home. However these days, most people spend more of their time at the workplace than at home (Visser, 2006:3). Therefore when a colleague dies or one is grieving a death or a loss, the impact on his or her co-workers can be tremendous (Dyer, 2002:1). The death of an employee can bring the workplace activity to a halt, because anyone who knew the person will experience some degree of shock and anxiety.

The workplace could therefore be a significant support system that could help a person to cope with the loss. However, the manner in which grief and loss are managed in the workplace could determine whether the employees' experiences of this loss are dealt with positively or negatively.

The aim of this article is therefore to provide (1) a brief theoretical background on employee bereavement, its impact in the workplace as well as bereavement support within the workplace; and (2) to report on the results of an empirical study on the need for a bereavement support programme at a healthcare institution.

\section{DEFINITION OF KEY CONCEPTS}

\section{Bereavement}

The National Cancer Institute (2006:11) defines bereavement as a state of sadness, grief and mourning after the loss of a loved one, while the Webster's New World Medical Dictionary (2003:40) describes it as the period after a loss during which grief is experienced and mourning 
occurs. It is emphasised that the time spent in a period of bereavement depends on how attached the person was to the person who died, and how much time was spent anticipating the loss.

It seems thus as if bereavement is the period after loss when a person is attempting to deal with his or her feelings and the sense of loss of someone or something close to them.

\section{Support}

The concept of support has been defined as "to give aid or encouragement to a person or cause" (American Heritage Dictionary of the English Language, 2004:190), or "the activity of providing for or maintaining by supplying with money or necessities" (Webster, sa:sn). In the context of this paper support refers to the offering of assistance, through the activity of a bereavement support programme, to employees who have lost a loved one.

\section{Programme}

According to Cassell's English Dictionary (2000:986), a programme refers to "A list of the successive items of any entertainment, public ceremony, conference, course of study plus other relevant information". Cusworth and Franks (1993:1) define it as resembling a project "in that it is a set of objectives designed to facilitate the achievement of specific objectives but generally on a larger scale and over a longer time frame". The authors define a programme on an organized and well-planned schedule or agenda aimed at achieving a particular goal or objective. In the context of this paper a programme means a well-planned schedule aimed at supporting employees in the workplace during their time of bereavement.

\section{BEREAVEMENT IN THE WORKPLACE}

These days most people spend more of their waking hours at the workplace than at home. People who work together may become close, like an extended family. Therefore when a colleague dies or one is grieving a death or a loss, the impact on his or her co-workers can be tremendous and can influence the workplace in a variety of ways. According to Dyer (2002:1), productivity can be compromised and the dynamics of the workplace can change. When the death is unexpected, as in a violent act or an accident, the grief response can be quite traumatic for the survivors, further impacting on the work situation.

\section{Impact of grief and bereavement on the bereaved person}

One of the difficult certainties of life is that at certain times it will be touched very deeply by the human sense of loss. The death of a parent, sibling, family members, friends and working colleagues affects the workplace in many different ways. McGuiness (2007:9) mentions that apart from the grief itself, it can create a sense of instability, of worry, concern and unease. These emotions can express themselves in many different forms in the workplace and can have deeply personal and wider impacts because of their painful reality.

After the death of a close relative or friend, it is customary for the bereaved person to be allowed a few days of compassionate leave from work. This is often not sufficient time for the bereaved person to recover emotionally, because returning to the workplace could be an overwhelming burden in addition to their grief. McGuiness (2007:9), the Canadian Mental Health Association (2004:1) as well as King and Tellioglu (2007:1) state that although people who are grieving continue to work and socialise, the experience of loss inevitably affects their productivity at work; they have identified the following effects in some employees:

- Poor concentration, which results in slower production rates and poor performance; 
- Social withdrawal and employees isolating themselves from co-workers;

- Inappropriate workplace behaviour and inability to control emotions and temper, which affects co-workers and in turn productivity;

- Decreased energy and extreme tiredness, which could result in workplace accidents;

- Unreliability;

- Difficulty in making decisions;

- Anxiety and helplessness.

Furthermore, management and co-workers may not understand the difficulties that grief can cause and the bereaved employee may worry that he or she will lose his or her job as a result of reduced work performance, or because of extra time taken off from work. In this regard Grief Reactions (2007) notes that bereaved workers may become anxious about the fact that they have developed a reputation for:

- wasting time;

- taking too much sick leave;

- being bad tempered, unreliable, unstable;

- receiving special treatment.

These feelings may lead to a reaction in which the bereaved employee becomes tempted to give up his or her job because of a fear of failure or to reduce the pressure on him-/herself.

\section{Impact of grief and bereavement on co-workers}

Grief or bereavement in the workplace has a significant impact on co-workers as well. Coworkers can be distracted by emotions that range from confusion to chaotic pain, from dismay to devastation (Grief in the Workplace, 2000:1).

According to Morrell (2000:2), one of the major challenges of dealing with death in the workplace is that grieving is not well understood, and managers and employees do not have enough information or awareness to respond appropriately. Employers often underestimate the effect of an illness or death on the workers around the bereaved person. Employers may not understand or recognise the extent to which:

- employees form emotional attachments with one another; in some cases friendships with coworkers can be more important than familial relationships;

- problems associated with grief, for example, absenteeism or personal conflict may surface months after the loss;

- the grief process can influence the productivity level of the organisation.

According to the Suicide Information and Education Centre (SIEC) (2000:1), suicide is a painful loss for surviving family and friends. However, the effects of a co-worker's suicide can be equally profound within the workplace. Co-worker's grief reactions are often the same as those of family or friends and can include:

- shock or disbelief at the death itself, and often at the cause of death;

- shock may be expressed in many ways including violent outbursts, dazed withdrawal and the inability to take in the reality of the death;

- anger which may be directed at co-workers, management, healthcare providers, and even the deceased colleague. Co-workers may express anger that the colleague never confided in them about how desperate they felt. They may also be angry or experience a sense of 
personal rejection, because they feel that they were not given the opportunity to help their colleague;

- guilt over things which may or may not have been done or said. Some guilt may be related to regret about insufficient care and concern for their colleague.

People go to work expecting business as usual. At the end of the day they go home to their families. The last thing anyone expects is for a co-worker to die at the workplace, either from natural causes, or as a result of a tragic event. When a death occurs in the workplace, the normally orderly environment can quickly turn into one of chaos. If the death occurred as a result of an industrial incident, fire, murder or similar tragic incident, workers have to deal with additional concerns as well as the shock, such as the death of a co-worker and the sense of a loss of safety in the work environment. Workers and management may become concerned about how and why the incident occurred and what sort of steps are being taken to ensure that another accident will not happen and/or that security is being increased to protect them from future incidents of violence. Death in the workplace may result in feelings of anger, guilt, unease, fear for personal safety plus the pervasive need for someone or something to blame (Dyer, 2002:2).

According to Dyer (2002:1), grief upsets workers and disrupts the work environment. Unfortunately, most businesses cannot afford to halt production, sales or services to accommodate the grief response. Instead they continue on in "business as usual" mode.

\section{Bereavement support in the workplace}

Many workplaces are not enabled to handle an employee's loss and grief. According to Rajesh (2006:2), most human resource policies are woefully inadequate in terms of support for a bereaved or distress employee.

When an employee experiences a loss or an illness, their ability to deal with the grieving process can become even more prolonged if the person does not feel supported by his or her manager, supervisor or employer. Those who feel cared for and supported are more likely to have improved recovery (Dyer, 2002:1).

How a company treats its grieving employees strongly affects how employees perceive the company (Gould, 2004:1). Without proper training, managers and colleagues may end up mismanaging the situation in a variety of ways, e.g. an employee may receive a poor performance rating instead of needed help. Inappropriate comments such as, "It's God's will," or, "Isn't it time you got over this?" can have such a negative impact that a valued employee may end up resigning. Vincent (2004:2-3) confirms this by stating that job performance and morale can suffer if managers are not educated about dealing with grief and prepared to respond appropriately. The key is for supervisors to balance the emotional needs of griefstricken employees with the work demands of their organisation. Employees who experience a compassionate response to their situation often become intensely loyal, while co-workers who observe supervisors providing a well-informed, flexible response to grief can be positively affected as well. From a practical point of view Vincent (2004:2-3) recommends the following actions that supervisors can take to support bereaved employees:

- Purchase a sympathy card, write a personal message, and pass it around the office;

- Hold a meeting with the entire workgroup to brainstorm ways to help;

- Talk with the employee before he or she returns to work to help ease the re-entry; 
- Become familiar with the stages of grief and help educate employees by providing access to brochures or materials from Employee Assistance Practitioners;

- Work with the bereaved employee to renegotiate work expectations and set up regular times to check on progress;

- If possible, allow flexible working hours or a leave of absence;

- Encourage employees to get support through counselling, bereavement support programmes or from clergy members.

Smith (Sa:1-2) points out that deaths do occur at work, people often receive the news of a relative's death while at work, and employees often have to remain on the job after they learn of a colleague's death. Unfortunately, we also live in a society that does not really understand nor feel comfortable with the grieving process. Consequently, if an employee's grief is responded to at all, it is often in awkward and uncertain ways. Employees do not expect management or human resource personnel to remedy their grief, but they do expect them to respond to and respect their loss. Smith (Sa:1-2) emphasises the following valuable aspects that may be of benefit to managers who are confronted with employees coping with a loss:

- Recognizing the grief: Recognition can be as simple as a letter of condolence from a supervisor, or flowers sent to the funeral or mention of the employee's loss in a newsletter. Few things hurt and offend more than to experience a loss and have no one acknowledge it;

- Responding to the grief: Managers should respond and link with an appropriate resource (e.g. EAP practitioner) that can educate and debrief bereaved employees to minimise the emotional impact;

- Respecting the grief: Respecting an employee's loss is an important way to demonstrate respect for that person as an individual. It also enhances morale when staff realise that what happens in their lives matters to their managers as well. Respect develops when managers implement such actions as outlined above. It shows employees the sincerity of the concern when assisting them in times of loss.

Adding to the above points, the Suicide Information and Education Centre (2000:2) provides advice on additional support that employers can give to their bereaved staff including:

- offering concrete and specific help. Often the newly bereaved are too overwhelmed to know what they need. They may require information on bereavement leave, benefit entitlements, paperwork associated with final pay cheques, medical claims or life insurance policies;

- being flexible about time-off, especially in the first year after bereavement. Some employees will require more leave than the company policy allows;

- redistributing those parts of the bereaved employee's job which must be done. Eliminating the pressure to perform is one way of demonstrating support for a grieving employee. At the same time the employer must be aware of the additional strain this can create for other staff who take on new duties temporarily or permanently;

- recognising that some employees may return to work too quickly to avoid dealing with their grief. In the long-term this method of coping is counterproductive as it can lead to complicated grief reactions. 
All the above information on appropriate responses of management to bereaved staff could be regarded as unstructured support programmes in the workplace. According to Lynn (2001:926927), unstructured programmes may further include:

- acknowledgement of the death;

- acquiring knowledge about the stages of bereavement;

- providing appropriate information;

- being a partner in the process by showing support;

- follow-up through a personal phone call, follow-up card or letter and attendance at the funeral or memorial service;

- pastoral support services.

However, structured bereavement support programmes should also be available in the workplace. Structured programmes focus on specific issues and include formal structures with the goal of helping the bereaved to achieve satisfactory closure. Structured programmes, according to Lynn (2001:928), are most effective when they are tailored to the specific needs of the bereaved employee and could include the following features.

\section{Written handouts}

Written handouts about death and bereavement can help the bereaved, family members and coworkers. The amount and type of information given to the bereaved, family members and coworkers must be adjusted to meet their needs. Handouts raise awareness of feelings and fears that the bereaved, family members and co-workers often experience about dying and the grieving process. Adequate time to discuss issues raised in written materials is important. According to King and Tellioglu (2007:2), the most important aspect for grieving people is learning to cope with their loss and so the following information or "coping tips" could be included in written handouts.

- Avoiding isolation. It is important for grieving people to talk to others and explain how they are feeling. They must not be afraid to ask for support.

- Taking care of physical health. People who are grieving still need to see a physician when they are feeling unwell. Most physical complications of grief can be eased by eating properly, exercising and getting plenty of rest.

- Postponing major decisions when possible. Grief may interfere with judgment.

Co-workers can also take certain steps to help bereaved colleagues cope with grief.

- Listening - people who are grieving need to share their thoughts and feelings with others.

- Not offering false comfort. Comments such as "he's in a better place now", or "at least she is not suffering anymore" often do not help and may make the grieving person feel even worse.

- Offering practical help. Grieving individuals may benefit from assistance with household chores and errands.

\section{Availability of professional support}

Grief is a complex psychological process that may not be always clearly and fully recognised by the bereaved, family members and co-workers. Professionals such as social workers, psychologists and psychiatrists are helpful in understanding bereavement and grief. Professional help and timely debriefing can assist in stabilising the workplace and ensuring that 
anyone needing specific grief support gets the assistance they need. Debriefings allow those involved to explore the impact of the loss, while dispelling rumours, identifying ways to assist family and friends of the deceased and, where desired, putting company policies and procedures in place to assist when the need arises.

According to Pilgrims Hospice (2008:1), grief counselling helps mourners with normal grief reactions to work through the tasks of grieving. The goals of grief counselling therefore include:

- helping the bereaved to accept the loss by helping him or her to talk about the loss;

- helping the bereaved to identify and express feelings related to the loss (e.g., anger, guilt, anxiety, helplessness and sadness);

- helping the bereaved to live without the person who died and to make decisions alone;

- helping the bereaved to separate emotionally from the person who died and to begin new relationships;

- provide support and time to focus on grieving at important times such as birthdays and anniversaries;

- describing normal grieving and the differences in grieving among individuals;

- providing continuous support;

- helping the bereaved to understand his or her methods of coping;

- identifying coping problems the bereaved may have and making recommendations for professional grief therapy.

\section{Support groups}

Lynn (2001:928) emphasises the value of formal bereavement support groups that may help the bereaved and family members reach closure. Professionals with experience, specialised education and knowledge about grieving usually lead these support groups and within the support groups grieving individuals receive support from other group members.

\section{Structured workplace bereavement support programmes}

Structured formal workplace bereavement support programmes can also be valuable resources for organisations to minimise the effects of grief and bereavement in the workplace. Hartley (Sa:1-2) and Machin (Sa:2) recommend that the following discussion themes can be incorporated in these programmes: personal fears and phobias around death, dying and loss; impact of bereavement and benefits of a supported workforce; manifestations of grief in the workplace; listening and communication skills; theoretical frameworks which increase the understanding of people's grief reactions; helping models; loss and trauma in the workplace.

Various forms of support can thus be offered to grieving employees in the workplace. The appropriateness of the support, however, could be determined by the sources of the grief of employees, the needs of the employees, the willingness of the organisation to provide support and the availability and affordability of support resources to organisations. However, lack of support or inappropriate support could have extremely negative consequences. Offering workplace bereavement support programmes will not only benefit grieving employees, but also the organisation through increased loyalty, morale and job performance of employees, which will ultimately result in increased organisational profits. 


\section{THE RESEARCH STUDY}

Based on the above discussion there appeared to be a need for workplace bereavement programmes. Therefore an empirical study was conducted with the goal to investigate the need for an employee bereavement support programme at a healthcare institution.

The research study was guided by the following research question:

What is the need for an employee bereavement support programme at the healthcare institution?

\section{Research methodology}

In the context of applied research the study was conducted in terms of a quantitative paradigm, because the purpose of the study was to investigate in a controlled and objective manner (Welman, Kruger \& Mitchell, 2005:8-9), through a questionnaire, the need for an employee bereavement support programme at the healthcare institution. The research design for the study was a randomised cross-sectional survey design, which is commonly used for surveys in the needs assessment phase of research (Fouché \& De Vos, 2005:137).

A sample of 70 respondents $(16 \%)$ of all the employees at the health institution was selected by using systematic sampling (Strydom, 2005:200). This non-probability sampling technique was appropriate, because a list of all the employees at the healthcare institution was available, which implied that the researchers could randomly select the first respondent from the list and afterwards use a particular interval to select the sample which represented the population.

Based on the fact that questionnaires are used primarily in survey research (Babbie, 2007:244), the data-collection method used in this study was hand-delivered questionnaires. The researchers distributed each questionnaire together with an envelope and requested the respondents to complete and place the questionnaire in the sealed envelope into a box outside the EAP office at the specific healthcare institution. This procedure helped to address the important ethical issues of confidentiality, privacy and anonymity of the respondents (Marlow, 2005:330).

The data collected through the questionnaire were then processed, analysed and interpreted using univariate analysis (Welman et al., 2005:231). The variable that was analysed and interpreted was the employee's need for an employee bereavement support programme at the healthcare institution. After analysis, the data were displayed and summarised in table format and in various graphical presentations.

\section{RESEARCH FINDINGS AND DISCUSSION}

The collected data will be divided into three sections, namely (a) demographic information of respondents; (b) respondents' experiences of grief and bereavement; and (c) bereavement support.

\section{SECTION A: DEMOGRAPHIC PROFILE OF RESPONDENTS}

\section{Gender and age}

The gender distribution of the respondents was 33\% males and 67\% females. Although the age of respondents ranged between 18-60 years, the majority of respondents ranged between 25-49 years. 


\section{Marital status}

Marital status is depicted in Table 1.

TABLE 1

MARITAL STATUS

\begin{tabular}{|l|c|}
\hline Married & 29 \\
Never married & 33 \\
Divorced & 4 \\
Separated & 3 \\
Widowed & 1 \\
\hline TOTAL & $\mathbf{7 0}$ \\
\hline
\end{tabular}

\section{Language}

The most dominant home language (54\%) of the respondents was IsiZulu, followed by $40 \%$ respondents with English as their home language and Afrikaans, Sesotho and IsiNdebele 2\% each. It is important to note that in the context of this study, despite IsiZulu being the dominant home language, English was the preferred language of communication to ensure that all employees in the health care institution have a common understanding.

\section{Career components}

The majority of the respondents $(67.14 \%)$ were from the nursing component of the institution, $17.14 \%$ from finance and systems, $11.43 \%$ from the allied health professions, $2.86 \%$ from human resource management and $1.43 \%$ from other hospital components. As nursing is the largest component in the specific healthcare institution, the profile is a good representation of the distribution of employees as well as the different sectors of the institution.

\section{SECTION B: RESPONDENTS' EXPERIENCES OF GRIEF AND BEREAVEMENT}

In this section the researchers established the respondents' experiences of grief and bereavement, because this information was vital in order to ensure that their responses regarding the need of a bereavement support programme were primarily based on their own experiences and not biased perceptions. The following information was thus relevant.

\section{Number of deceased acquaintances}

Data indicated that only 3 (4.29\%) of the respondents did not know anyone who had died in the previous three years before the investigation, 17 (24.29\%) knew one person, 7 (10\%) knew two people, a further 17 (24.29\%) knew three deceased acquaintances, followed by 7 (10\%) who knew at least four deceased acquaintances, $12(17.14 \%)$ who knew five and $7(10 \%)$ who knew more than five deceased acquaintances in the previous three years. These statistics revealed that more than $50 \%$ of the respondents knew 3 or more people who had died in the previous three years before the investigation.

\section{Relationship with the deceased}

An equal percentage (35.7\%) of respondents indicated their relationship with the deceased being a family member or a relative, $38.6 \%$ a friend, $25.7 \%$ co-worker, $12.9 \%$ a patient and $1.4 \%$ with persons from other categories. According to King and Tellioglu (2007:1), the course of normal grief reactions is determined by a number of factors, one being the closeness of the attachment or relationship with the deceased. From these statistics it can noted that majority of 
respondents had lost family, relatives and friends who were close to them, which has a significant impact on the grieving process and the support required.

\section{Causes of death}

Respondents indicated that $77.1 \%$ of the causes of death were natural and expected, $40 \%$ were natural but sudden, $18.6 \%$ were accidental, $27.1 \%$ were violent, $4.3 \%$ were suicide and $1.4 \%$ were a result of other causes. Gill, Smith and Segal (2007:4), mention that grief tends to be mixed with trauma when a loss is sudden and unexpected, such as a fatal heart attack, suicide, an accident or murder. Grief is a normal reaction to loss, with its symptoms diminishing over time, but trauma is a disabling reaction that can block the grieving process, disrupt your life, and leave you psychologically vulnerable. The researchers noticed that the percentage of the natural sudden deaths, accidental deaths and violent deaths was quite high, which could therefore have impacted on the respondents' responses on the need for an employee bereavement support programme.

\section{SECTION C: BEREAVEMENT SUPPORT}

This section contains the core findings on the need for an employee bereavement support programme. However, in order to determine the need for and importance of such a programme in the workplace, data should be interpreted in the context of the respondents' experience of bereavement support.

\section{Support offered}

Sixty-eight percent of respondents indicated that they did receive some sort of support after their loss and 32\% did not. DeSpelder and Strictland (1999:256) state that the experience of grief varies according to the amount of social support available. The researchers therefore found these statistics to be very positive as they indicate that the respondents have some support network already.

\section{Effects of lack of support on work performance}

Data on the effects of lack of support on work performance is depicted in Table 2.

TABLE 2

EFFECTS OF LACK OF SUPPORT ON WORK PERFORMANCE

\begin{tabular}{|c|l|c|}
\hline $\begin{array}{c}\text { Number of respondents } \\
\text { that did not receive any } \\
\text { support }\end{array}$ & \multicolumn{1}{|c|}{$\begin{array}{c}\text { Effect on work } \\
\text { performance }\end{array}$} & $\begin{array}{c}\text { Number of } \\
\text { respondents affected }\end{array}$ \\
\hline 8 & Difficulty concentrating & 8 \\
\hline 9 & Extremely emotional & 9 \\
\hline 3 & Affected my attendance & 3 \\
\hline 3 & Affected my motivation & 3 \\
\hline 0 & $\begin{array}{l}\text { Affected my relationship with my } \\
\text { colleagues }\end{array}$ & 2 \\
\hline 2 & Did not affect my work performance & 1 \\
\hline 1 & Other effects & \\
\hline
\end{tabular}


According to King and Tellioglu (2007:1) some effects of grief and bereavement on employees are poor concentration, which results in slower production rates and poor performance; employees isolating themselves from co-workers; inability to control emotions and temper, which affects co-workers and in turn productivity; and extreme tiredness, which could result in workplace accidents and unreliability. Table 2 indicates that 26 respondents who did not receive any support during their grief and bereavement experienced some of the effects indicated by King and Tellioglu (2007:1), such as difficulty in concentrating, being extremely emotional, and the fact that their attendance, motivation and relationships with their colleagues were affected. The researchers are of the opinion that these statistics give an indication of the importance of a bereavement support programme in the workplace.

\section{Effect of support received}

Of the $68 \%$ of respondents who received support, as indicated above, the data in Table 3 highlight that 67 responses were received stating that they benefited from the support they received in one or more categories.

TABLE 3

EFFECT OF SUPPORT RECEIVED

\begin{tabular}{|l|c|}
\hline \multicolumn{1}{|c|}{ Effect of support } & Number of responses \\
\hline Less stressed & 14 \\
\hline Emotionally stronger & 13 \\
\hline Better coping strategies & 8 \\
\hline More relaxed & 5 \\
\hline Able to deal with grief and move on & 26 \\
\hline Other & 1 \\
\hline TOTAL & $\mathbf{6 7}$ \\
\hline
\end{tabular}

The fact that respondents indicated that the support they received has the effect that they felt to a large extent less stressed, emotionally stronger and able to deal with their grief and move on is positive and an indication of the importance of bereavement support. There is recognition that sharing the grief does not take it away, yet it can assist the bereaved with their grief. The expression of grief and bereavement forms part of the mourning rituals that help the bereaved feel cared for and supported, and this support is essential (DeSpelder \& Strictland, 1999:562).

\section{Follow-up support services required}

The majority of respondents $(62.50 \%)$ would have liked to have received follow-up support services. The importance of further bereavement services is also highlighted by Jackson (1996:2-11), who refers to extensive documentation which demonstrates that follow-up or further bereavement support results in increased health status of the bereaved. According to him, studies have found that a perceived lack of support after bereavement raises the risk of health consequences from less than $20 \%$ to almost $86 \%$. The bereaved with follow-up support have further shown fewer symptoms of distress physically and psychologically, fewer visits to the doctors and have higher health status scores. This corresponds with Faulkner's (Sa:sn) statement that follow-up support programmes can assist the bereaved to continue relationships 
with the deceased after death, assist and promote openness within families, and offer empowerment with a view to liberating and educating the bereaved to find coping strategies in order to deal with their grief. It seems thus as if the availability of further bereavement or follow-up services should be part of bereavement support programmes.

The need for an employee bereavement support programme

FIGURE 1

THE NEED FOR AN EMPLOYEE BEREA VEMENT SUPPORT PROGRAMME

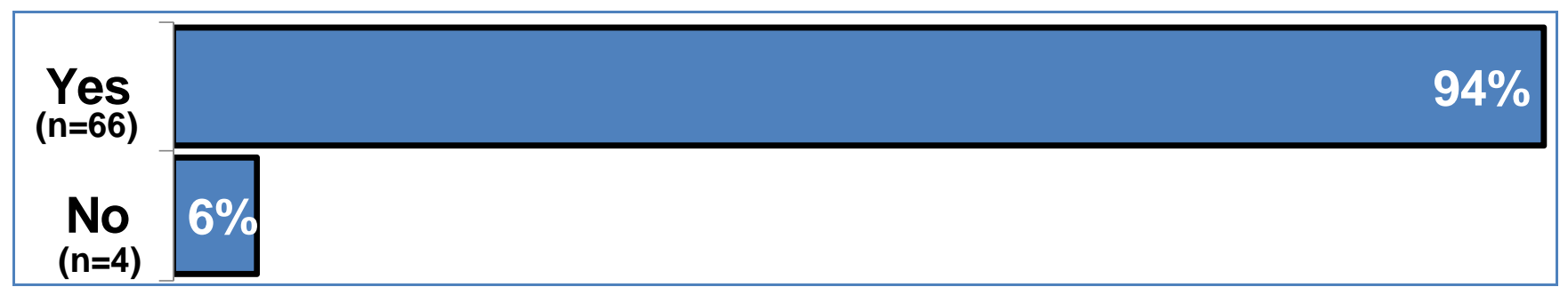

Despite majority of the respondents receiving some sort of bereavement services as indicated above and $95 \%$ of the respondents benefiting from the support received, as indicated in Table $3,66(94 \%)$ of the respondents felt that there is definitely a need for an employee bereavement support programme at the institution and only $4(6 \%)$ felt that there is no need for such a programme. These statistics correspond with the literature that a bereavement support programme in a workplace is necessary and can be extremely beneficial for employees (Dyer, 2002; Lev \& McCorkle, 1998; Lynn, 2001; Pilgrims Hospice, 2008; Vincent, 2004).

On the basis of these statistics the researchers can answer the research question: what is the need for an employee bereavement support programme in the workplace? These statistics indicate that the employees of the institution definitely feel that there is a need for a bereavement support programme. However, further important recommendations regarding the content of an employee bereavement support programme in the workplace were also revealed.

\section{Content of an employee bereavement support programme}

FIGURE 2

CONTENT OF AN EMPLOYEE BEREAVEMENT SUPPORT PROGRAMME

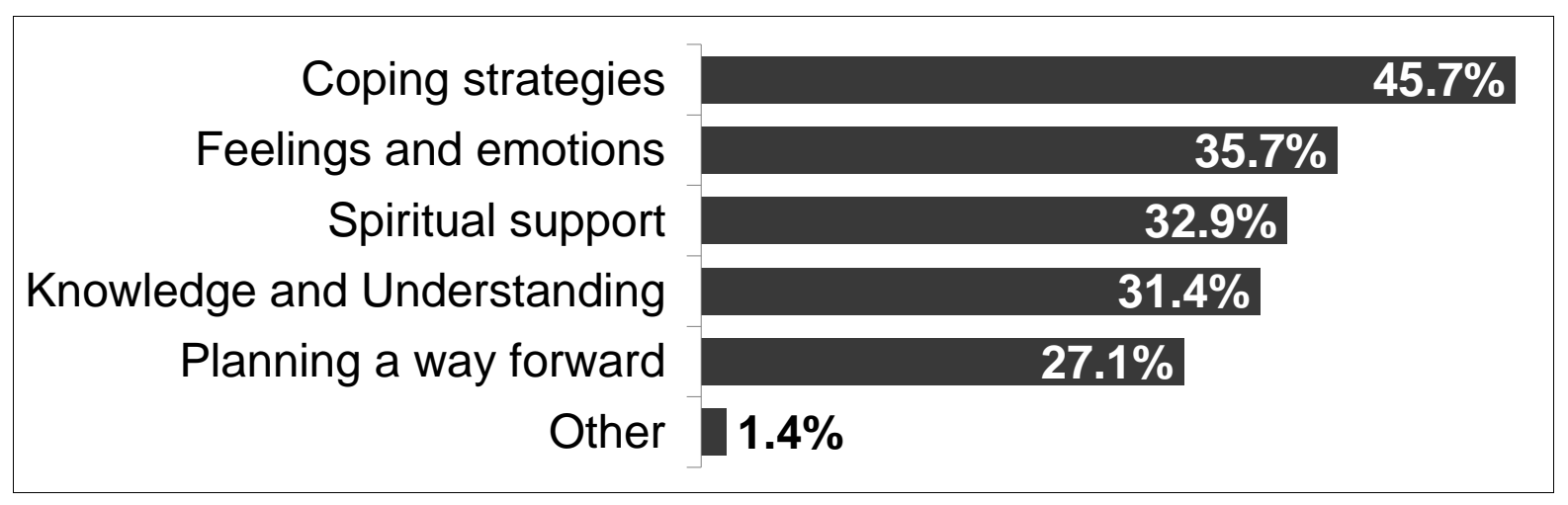

The researchers are of the opinion that the content of any bereavement support programme is crucial and must be carefully planned and prepared for in order to address the needs of the respondents. Figure 2 illustrates that $45.70 \%$ of the respondents would like the inclusion of coping strategies in the programme, $35.70 \%$ want to discuss feelings and emotions in relation to bereavement, $32.90 \%$ would like spiritual support, $31.40 \%$ want more knowledge and 
understanding of bereavement, $27.10 \%$ would like to know how to plan a way forward without their loved one, and $1.40 \%$ would like other content included.

The respondents' needs, as reflected in Figure 2, correlate with Pilgrims Hospice's (2008:1) view of grief counselling and support, as discussed previously. The researchers support the Pilgrims Hospice (2008:1) view and therefore believe that the content of the employee bereavement support programme should include a combination of the categories indicated in Figure 2 or the programme should be adjusted to meet the needs of the employees, if necessary.

\section{CONCLUSIONS AND RECOMMENDATIONS}

Bereavement and grief are life-changing and universal experiences. People cope with the loss of a loved one in many ways. For some the experience may lead to personal growth and for others it could lead to deterioration in their normal functioning. There is no right way of coping with death. How a person copes with grief is affected by the person's cultural and religious background, coping skills, mental history, support systems and the person's social and financial situation.

Grief and bereavement in the workplace have vast consequences ranging from tiredness and lack of concentration of employees to increased employee absenteeism and decreased productivity and organisational profits. Grief and bereavement in the workplace occur not only as a result of the death of employee's loved ones, but also from significant life and work changes of employees such as retrenchments, downsizing and closure of companies, which are very realistic prospects, considering our country's current economy. The support given to bereaved employees can, however, minimise these effects of grief and bereavement in the workplace. Workplace bereavement support programmes are a method of support for bereaved employees and can be valuable resources for organisations.

Various forms of support can be offered to grieving employees in the workplace. The appropriateness of the support, however, could be determined by the sources of the grief of employees, the needs of the employees, the willingness of the organisation to provide support, and the availability and affordability of support resources in organizations. However, lack of support or inappropriate support could have extremely negative consequences. Offering workplace bereavement support programmes will not only benefit grieving employees, but also the organisation through increased loyalty, higher morale and improved job performance of employees, which will ultimately result in increased organisational profits.

In the light of the goal and findings of the research study as stated above, the researchers recommended the following:

- Management of an institution should form a bereavement committee comprising of relevant role players such as the EAP practitioner, the psychologist, social workers and spiritual leaders;

- The bereavement committee of an institution should plan and organise the development and implementation of an employee bereavement support programme;

- The bereavement support programme must be made available to all employees of the institution;

- The bereavement programme that will be implemented should be suitable to the needs of the employees in terms of the type, content and length of the programme;

- Follow-up or further bereavement services should be rendered to employees, if this is necessary; 
- Future studies should be conducted to evaluate the employee bereavement support programme after the programme has been developed and implemented in an institution.

\section{REFERENCES}

AMERICAN HERITAGE DICTIONARY OF THE ENGLISH LANGUAGE $\left(4^{\text {th }}\right.$ ed) 2004. USA: Houghton Mifflin Company.

BABBIE, E. 2007. The practice of social research $\left(11^{\text {th }} \mathrm{ed}\right)$. USA: Thomson Learning, Inc.

CASSELL'S ENGLISH DICTIONARY. 2000. Great Britain: Mackays.

CANADIAN MENTAL HEALTH ASSOCIATION. 2004. Bereavement in the workplace. Canada: Centre for Suicide Prevention.

CUSWORTH, J.W. \& FRANKS, T.R. 1993. Managing projects in developing countries. [S1:sn].

DESPELDER, L.A. \& STRICTLAND, A.L. 1999. The last dance $\left(5^{\text {th }}\right.$ ed). California: Mayfield Publishing Company.

DYER, K.A. 2002. How to cope with loss, grief, death \& dying - professionally \& personally. USA: California State University.

FAULKNER, A. 1993. Developments in bereavement services. In: CLARK, D. (ed) The future for palliative care: issues of policy and practice. Buckingham: Open University Press.

FOUCHÉ, C.B. \& DE VOS, A. 2005. Quantitative research designs. In: DE VOS, A.S., STRYDOM, H., FOUCHÉ, C.B. \& DELPORT, C.S.L. Research at grass roots: for the social sciences and human professions. Pretoria: Van Schaik Publishers.

GILL, E.J., SMITH, M. \& SEGAL, J. 2007. Coping with grief and loss: guide to grieving and bereavement. [o]. Available: http://www.copingwithgriefandloss.html [Accessed: 27/02/2008].

GOULD, M. 2004. Handling bereavement: mourning death in the workplace. New Jersey: Princeton Group.

GRIEF IN THE WORKPLACE. 2000. Eckert: Bereavement Publications, Inc.

GRIEF REACTIONS ASSOCIATED WITH THE WORKPLACE. 2007. [o]. Available: http://www.workplace.html [Accessed: 07/08/2007].

HARTLEY, J. [Sa]. Grief in the workplace. United Kingdom: Talking Life Seminars.

JACKSON, I. 1996. Critical care nurses' perceptions of a bereavement follow up service. Intensive and Critical Care Nursing, 12:2-11.

KING, S.A. \& TELliOGLU, T. 2007. Grief. [o]. Available: http://www.Grief1.mht [Accessed: 27/02/2008].

LEV, E.L. \& McCORKLE, R. 1998. Loss, grief and bereavement in family members of cancer patients. Seminars in Oncology Nursing, 14(2):145-151.

LYNN, J. 2001. Serving patients who may die soon and their families. JAMA, 285:925-932.

LINDSTROM, T.C. 1983. Good grief: adapting to bereavement. Norway: University of Bergen. 
MACHIN, L. [Sa]. Bereavement and loss in social care \& bereavement in healthcare. United Kingdom: Talking Life Seminars.

MARLOW, C.R. 2005. Research methods for generalist social work. London: Thomson Brooks/Cole.

McGUINESS, B. 2007. Grief at work: developing a bereavement policy. Ireland: Irish Hospice Foundation.

MEDICINENET.COM. 2007. Bereavement. [o]. Available: http://bereavement-Mental Health Disorders on MedicineNet.com [Accessed: 13/08/2007].

MORRELL, S.L. 2000 .Grief in the workplace. British Columbia: Westwood Dynamics.

NATIONAL CANCER INSTITUTE. 2006. Loss, grief and bereavement. [o]. Available: http://cancer.gov/cancertopics/pdq/supportivecare.bereavement [Accessed: 07/08/2007].

PILGRIMS HOSPICE. 2008. Bereavement support: workplace debriefings. [o]. Available: http://www.XanadaHelps.org [Accessed: 07/02/2008].

RAJESH, S. 2006. Does your workplace allow for personal grief? India: The Hindu group of publications.

SMITH, J. [Sa]. Bereavement in the workplace: how to recognize it, respond to it and respect it. Nova Scotia: HR Links.

STRYDOM, H. 2005. Sampling and sampling methods. In: DE VOS, A.S., STRYDOM, H., FOUCHÉ,C.B. \& DELPORT, C.S.L. Research at grass roots: for the social sciences and human professions. Pretoria: Van Schaik Publishers.

SUICIDE INFORMATION \& EDUCATION CENTRE (SIEC). 2000a. Bereavement in the workplace. Canada: Canadian Mental Health Association.

SUICIDE INFORMATION \& EDUCATION CENTRE (SIEC). 2000b. Reactions to a colleague's suicide. Canada: Canadian Mental Health Association.

VINCENT, E. 2004. When an employee is grieving. USA: LifescapeSolutions.

VISSER, W. 2006. Meaning, work, and social responsibility. Available: http://www. meaning.ca/articles/visser-work-social-responsibility-sept03.htm [Accessed: 05/01/2006].

WEBSTER, M. [Sa]. Collegiate Dictionary. [S1: sn].

WEBSTER'S NEW WORLD MEDICAL DICTIONARY ( $2^{\text {nd }}$ ed). 2003. [S1:sn].

WELMAN, C., KRUGER, F. \& MITCHELL, B. 2005. Research methodology ( ${ }^{\text {rd }}$ ed). Cape Town: Oxford University Press.

WOOF, W.R. \& CARTER, Y.H. 1997. The grieving adult and the general practitioner: A literature review in two parts (part 1). British Journal of General Practice, 47:443-448.

Ms Vanagree Naidoo, Prof Rina Delport, Department of Social Work and Criminology, University of Pretoria, Pretoria, South Africa. 